\title{
Ara fa cinquanta anys: referents ideològics fundacionals del PSAN
}

\author{
Xavier Ferré Trill \\ Universitat Rovira i Virgili \\ Facultat de Ciències de l'Educació i Psicologia \\ Departament de Pedagogia \\ Campus Sescelades \\ Carretera de Valls, s/n \\ 43007 Tarragona \\ xavier.ferretrill@gmail.com \\ Fermí Rubiralta Casas \\ Doctor en Ciències Polítiques per la UPV-EHV \\ fermirubiralta@irakasle.eus
}

Resum: L'article estableix el context ideològic que explica el sorgiment del Partit Socialista d'Alliberament Nacional dels Països Catalans (PSAN). Per aquest motiu, s'hi concreta el marc polític i teòric que determinà (marxisme i alliberament anticolonial) i condicionà (moviment federalista europeu i maig del 1968) la nova organització. Així, el treball detalla la formació de la línia teòrica del partit i el sentit que cobrà en l'aplicació militant.

Paraules Clau: PSAN, societat nacional, alliberament nacional i de classe, marxisme i anticolonialisme, Països Catalans

\section{On the Fiftieth Anniversary of PSAN: \\ Foundational Ideological Guideposts}

Авstract: This paper establishes the ideological context that explains the emergence of the Socialist Party for National Liberation of the Catalan Countries [Partit Socialista d'Alliberament Nacional dels Països Catalans, or PSAN]. To this end, the paper pinpoints the political and theoretical framework according to which the new party was defined (Marxism and anti-colonial liberation) and influenced (the European federalist move-

Ferré Trill Xavier; RubiRalta CaSAs, Fermí (2019), «Ara fa cinquanta anys: referents ideològics fundacionals del PSAN». Cercles. Revista d'Història Cultural, 22, 193-220. ISSN: 1139-0158. ISSN-e: 1699-7468. DOI: 10.1344/cercles2019.22.1007. Data de recepció: 12/4/2019. Data d'acceptació: 17/5/2019. 
ment and the events of May 1968). Specifically, the paper looks in detail at the formation of the PSAN's theoretical line and the meaning given to this line through the activism of party members.

Keywords: PSAN, national society, national and class liberation, Marxism, anti-colonialism, Catalan countries

\section{Introducció}

Les recerques al voltant del Partit Socialista d'Alliberament Nacional dels Països Catalans (PSAN) són encara prou minses. Aquesta situació pot explicar-se per la deriva cap a estudis d'un sector d'organitzacions i moviments antifranquistes en detriment de formacions l'anàlisi de les quals ha restat minoritzada, o "demonitzada», en el conjunt de les ciències socials. ${ }^{\text {I }}$

Aquesta òptica - limitar l'estudi a organitzacions essencialment antifranquistes - pot haver limitat la reflexió entorn d'organitzacions — intel.lectuals col-lectius - que no conceberen la finalitat de la lluita amb l'oposició a una dictadura, sinó que orientaren la seva estratègia cap a la confrontació envers un estat concebut com a «estat nació». Es tracta, doncs, de tota una altra òptica d'anàlisi, que situa l'epicentre de la contextualització teòrica en la concepció nacional com a fet essencialment polític: oposició a les dinàmiques de «modernització cultural-ideològica» i repressiva de l'Estat espanyol.

Les principals recerques entorn del partit independentista són deutores de la investigació de Fermí Rubiralta en un doble sentit: anàlisi estasiològica i política, i comparació amb altres moviments

I És essencial Edward A. Tiryakian, "Nacionalismo, modernidad y sociología», dins Alfonso Pérez-Agote (ed.), Sociología del nacionalismo, Bilbao, Eusko Jaurlaritza, I989, pp. I53-I56.

Cercles. Revista d'Història Cultural, 22 (2019), 193-220.

ISSN: 1139-0158. ISSN-e: 1699-7468. DOI: 10.1344/cercles2019.22.1007. 
d'alliberament nacional —essencialment l'independentisme gallec i basc. ${ }^{2}$ Des d'un vessant de sociologia política —més projectiu, doncs-, Roger Buch situa la recerca al voltant del PSAN entorn de les derivacions orgàniques - tenint en compte, però, les gradacions "generacionals», de context polític i de diferenciació organitzativai d'aportacions politicointel.lectuals fins entrat el segle XXI. Una orientació semblant, però concretant la relació entre independentisme i marxisme, ha estat aportada per l'historiador Albert Botran. ${ }^{3}$

Per a l'origen fundacional del partit al País Valencià — endegat a la Universitat Catalana d'Estiu, a Prada de Conflent, l'agost de 1973, i culminat a l'Horta de València, al Vedat de Torrent, per Falles de I974-, comptem amb l'aportació vivencial de Josep Guia. ${ }^{4}$

Pel que fa a anàlisis polítiques (en una certa clau «autobiogràfica») que fixen el context ideològic dels anys seixanta, i que serveixen per comprendre el pas de la base militant del Front Nacional de Catalunya (FNC) al PSAN, la revista Quaderns d'Alliberament edita-

2 Fermí Rubiralta i CaSas, Origens i desenvolupament del PSAN. 1969-1974, Barcelona, La Magrana, 1988; Fermí Rubiralta I CASAS, Una història de l'independentisme politic català. De Francesc Macià a Josep Lluís Carod-Rovira, Lleida, Pagès, 2004, pp. 139-148, i Fermí Rubiralta i Casas, El nuevo nacionalismo radical. Los casos gallego, catalán y vasco, 1959-1973, Donostia - Sant Sebastià, Tercera Prensa - Hirugarren Prentsa, 1997, Gakoa.

3 Roger Buch i Ros, El Partit Socialista d'Alliberament Nacional (PSAN). 1974-I980, Barcelona, Institut de Ciències Polítiques i Socials, 1995; Roger Buch i Ros, L'herència del PSAN. Les aportacions humanes i ideològiques del Partit Socialista d'Alliberament Nacional dels Països Catalans (1968-1980) al sistema politic actual, Barcelona, Base, 2012, i Albert Botran I Pahissa, «El marxisme en l'independentisme i l'independentisme en el marxisme», dins Jaume Renyer i Alimbau, Enric Pujol i Casademont (dir.), Pensament politic als Països Catalans, 1774-20I4, Barcelona, CETC / Pòrtic, 2007, pp. 315-319.

4 Josep Guia I Marín, «La transició política al País Valencià (1974-I977) des d’una perspectiva independentista», dins Pelai PAGÈs I BlANCH (dir.), La transició democràtica als Països Catalans. Història i memòria, València, Publicacions de la Universitat de València, 2005, pp. 257-258. Pel febrer de 1976, el PSAN arrelà a les Illes, segons Bartomeu CANYELLes i Francesca Vidal, L'oposició antifranquista a les Illes, Palma, Moll, 1977, pp. 57-6, i Antoni SerRA, Gràcies, no volem flors. Cròniques de la clandestinitat a Mallorca, Barcelona, La Magrana, 198I, pp. I55-157.

Cercles. Revista d'Història Cultural, 22 (2019), 193-220. ISSN: 1139-0158. ISSN-e: 1699-7468. DOI: 10.1344/cercles2019.22.1007. 
va al seu primer número — dedicat a la «qüestió nacional i lluita de classes»_- un article, a càrrec de fundadors que foren del partit, on es mostrava la trajectòria històrica de la lluita de classes en el marc de les contradiccions nacionals.' Josep Ferrer, militant de l'FNC i un dels fundadors del nou partit, ha aportat un context teoricopolític fonamental al voltant dels orígens fundacionals del PSAN (fins i tot útil per situar-lo en el moment polític en què eixí editat, el 1978). Cal destacar-ne el document El marxisme i el leninisme (1970), coetani a la fundació del PSAN. Eva Serra i Carles Castellanos, cofundadors de l'organització, aporten unes útils reflexions sobre moments previs i orígens fundacionals del PSAN i les polèmiques establertes als anys setanta amb partits — com el Partit Socialista Unificat de Catalunya (PSUC) — al si de plataformes com l'Assemblea de Catalunya fins a abastar el període I974-I982. ${ }^{6}$

\section{Context d'una praxi d'alliberament}

D'ençà de la fi de la Segona Guerra Mundial no semblaven obrir-se bones perspectives per al desenvolupament dels moviments subestatals europeus. "Diversas teorías sobre integración política», tal com recordava John Breuilly, «sugerían que los derechos democráticos, el desarrollo económico, la creación de una pauta nacional de política

5 Rafael Castellanos, Antoni Fernàndez i Josep Ferrer (1977), "Consciència nacional i lluita de classes als Països Catalans», Quaderns d'Alliberament (Barcelona, La Magrana), núm. I, 1977, pp. 9-25.

6 Josep Ferrer, Per l'alliberament nacional i de classe. Escrits de clandestinitat, Barcelona, Ciutat de Mallorca i València, Avançada, 1978 (per al document esmentat, pp. 75-83); Eva Serra, «Independentisme i nacionalisme d'esquerres», dins Xavier Bru de Sala, Carme Dropez, Exili interior, represa $i$ transició, Barcelona, INEHCA / Proa, 2003, pp. IO7II5, i Carles Castellanos I Llorenç, Reviure els dies. Records d'un temps silenciat, Lleida, Pagès, 2003, p. 75 i seg.

Cercles. Revista d'Història Cultural, 22 (2019), 193-220. ISSN: 1139-0158. ISSN-e: 1699-7468. DOI: 10.1344/cercles2019.22.1007. 
basada en un principio de clase deberían cortar la hierba bajo los pies del nacionalismo separatista.» ${ }^{7}$

Tanmateix, en l'entreforc dels anys cinquanta i seixanta hom assistí a una emergència renovada de moviments d'alliberament nacional, els quals tenien com a objecte ideològic i polític qüestionar la planta nacionalitària construïda des del model contradictori d'estat nació. Es tractava d'analitzar les bases geopolítiques dels estats, l'aplicació de les quals abocà al concepte d'opressió nacional com a resultant d'una política d'aculturació estatal envers les llengües nacionals històriques i d'una trajectòria d'ocupació militar. Aquesta reflexió, amb projecció a d'altres nacions minoritzades (especialment a Itàlia, l'Estat francès i la Gran Bretanya), prenia com a fonaments - a escala europea - els efectes del desenvolupament desigual i els processos d'estandardització promoguts per un model de creixement desigual del capitalisme.

La «sorpresa» produïda per aquesta paradoxa, és a dir, el sorgiment de moviments d'alliberament nacional a l'aleshores Europa Occidental —especialment entre els investigadors anglosaxonsn'explicava la gran quantitat d'estudis i la generalització a l'àmbit acadèmic de la denominació «nous nacionalismes» per referir-se a aquesta etapa de desenvolupament del moviment nacionalista subestatal. $^{8}$

De manera paral.lela, l'Estat espanyol conegué —entre I959 i I974- la cruilla a partir de la qual es desenvoluparen models de construcció nacional que interrelacionaven matriu cultural, lingüística, politització del conflicte nacional i relació amb d'altres proces-

7 John Breuilly, Nacionalismo y estado, Barcelona, Pomares-Corredor, I990, p. 294.

8 A banda de les obres de Tom NaIrn, Los nuevos nacionalismos en Europa, Barcelona, Península, 1979, i Edward A. Tiryakian i Ronald Rogowski, New nationalisms of the Developed West, Boston, Allen and Unwin, 1985, que utilitzen directament el terme «nous nacionalismes», una llarga llista d'autors han parlat d'aquest «réveil des nations» o «ethnic revival». 
sos internacionals de lluita anticolonial. Els focus d'aquests moviments radicaren, essencialment, a Galícia, el País Basc i, gradualment, als Països Catalans, amb concrecions regionals (per exemple, la derivació política del nou valencianisme com a referent d'ençà del darrer terç dels anys cinquanta).?

Els resultats d'un creixement econòmic «regionalment» polaritzat entre els anys seixanta i setanta — conseqüència de l'aplicació dels tres Planes de Desarrollo (1964-1967, I968-I97I, I972-1975) - foren subjectivats per focus nacionals com a efectes del nacionalisme de l'Estat (franquista), que instrumentalitzava políticament —estratègicament - processos migratoris forçats cap a les «periferies» industrialitzades com a einad'espanyolització. En part, el sorgiment d'organitzacions adscrites al model d'alliberament nacional fou, com veurem, la resposta a una «modernització» percebuda, per aquests focus de lluita, com a imposada i legitimada per l'Estat a fi d'anorrear societats nacionals que havien sofert una primera onada d'espanyolització i repressió sota el francofalangisme. ${ }^{\text {IO }}$

Ara bé, la resposta a aquesta «modernització inventada» (estatal) no era solament política. Un nou projecte nacional, com a comunitat imaginada, fou socialitzat per àmbits de reflexió, els assaigs i estudis dels quals caracteritzaren històricament l'evolució cultural i política de la formació social objecte d'estudi, i les actituds de les elits i les organitzacions polítiques davant el fet nacional. És en

9 Fermí Rubiralta i CASAs, El nuevo nacionalismo radical, I997, pàssim.

Io El millor plantejament metodològic que té en compte la dialèctica entre el «centre» (Estat) i la "periferia» (nacions subalternes) ha estat bastit per Francisco LeTAMENDiA, Juego de espejos. Conflictos nacionales centro-periferia, Madrid, Trotta, 1997, pp. 19-189. Aquest procés reactiu, gens original, d'altra banda, en fases anteriors del desenvolupament nacionalista mantindria molts punts de contacte amb el denominat «enfocament de la modernització», que han defensat autors com Ernest Gellner, a Thought and Change, Londres, Weidenfeld and Nicolson, I964, que recull les seves tesis originals, matisades amb posterioritat a Nations and Nationalism, Oxford, Basil Blackwell, I983.

Cercles. Revista d'Història Cultural, 22 (2019), 193-220.

ISSN: 1139-0158. ISSN-e: 1699-7468. DOI: 10.1344/cercles2019.22.1007. 
aquest context que cal situar, com a exemple, la influència entre militants del PSAN de l'assaig d'història Nosaltres, els valencians, de Joan Fuster (1962). Existia, doncs, una vinculació, si es vol indirecta, de compromís pel que fa a individualitats intel.lectuals amb el recobrament nacional dels pobles i nacions. La funció de l'intellectual, d'altra banda, es veié complementada per l'assumpció dels postulats per part de sectors d'estudiants universitaris, els quals, alhora, esdevenien subjectes polítics i, doncs, base amb pròpia capacitat d'elaboració teòrica i d'estratègia, en la qual la influència de les tesis alliberadores del II Concili Vaticà i el marxisme —o l'antropologia marxiana - tingué una funció referencial destacada en àmbits ideològics incipients.

La universitat esdevingué, doncs, espai de sociabilitat política primordial en el cas d'organitzacions «prepolítiques» que donaren lloc als partits més representatius de la radicalitat nacional-popular: Brais Pinto, que, en el cas gallec, pot ser considerat com l'antecedent de la Unión do Povo Galego (UPG), el 1964; ${ }^{\text {II }}$ Ekin (1952), indubtable precursora al País Basc, a finals de 1958, d'Euskadi ta Askatasuna (ETA), i el Bloc Escolar Nacionalista (BEN), fornal de militància universitària de l'FNC, d'una part substancial del qual sorgí el PSAN el I968.

Manifestacions culturals com les universitats d'estiu —els orígens de la Universitat Catalana d'Estiu (UCE), a Prada de Conflent (I968-1970) — poden circumscriure's en el context de presa de consciència nacional-regional en àmbits culturals i polítics.

Aquesta radicalitat política es palesà des de les característiques de cada formació social, però alhora ho feu amb objectius comuns. Així, a Galícia, al País Basc i a Catalunya, noves organitzacions -UPG, ETA i PSAN_ declararen llur component socialista i manifestaren

in Fermí Rubiralta i Casas, De Castelao a Mao. O novo nacionalismo radical galego (I959-1974): Orixes, configuración e desenvolvemento inicial da U.P.G., Santiago de Compostella, Laiovento, 1998. 
la seva voluntat de dirigir l'acció política envers les classes populars. Aquesta fita explica que tots aquests grups s'autopercebessin (si més no en el bastiment d'un imaginari referencial) com a continuadors de la tradició més conseqüent del seu respectiu corpus nacional, la qual cosa els reforçava per impulsar l'estratègia independentista. Una concepció, però, que recolzava sobre un ressort de defensa de la cultura i llengua nacionals, aleshores concebudes com a elements caracteritzadors d'una ètnia, que res no tenia a veure, és clar, amb el concepte depassat de «raça», defensat per elits supremacistes colonitzadores.

Cal dir, però, que l'òptica alliberadora —en embrió teòric i de propaganda - també es definia a la diàspora. Des de finals dels anys cinquanta havien aparegut a l'exili americà les primeres incitacions a lligar la qüestió nacional catalana amb l'emergent lluita descolonitzadora. Individualment, a l'Argentina, Antoni Cardona i Roca havia redactat el is d'abril de 1958 un document de quatre fulls titulat La tasca nacional del moment, on definia l'objectiu de «l'alliberament nacional» i la necessitat "de crear un organisme que encari la lluita per la independència nacional que podria anomenar-se Moviment d'Alliberament Català (MAC)», i dos anys més tard, el juny de 1960, publicava un pamflet d'un sol full amb el significatiu títol de L'acció armada per l'alliberament nacional, en el qual reivindicava la independència de Catalunya i preconitzava l'acció armada d'alliberament nacional. ${ }^{\mathrm{I2}}$ De forma parallela, el 1958 a Caracas, antics militants d'Estat Català (EC), com Amadeu Oller i Joaquim Juanola, havien posat en marxa el Moviment d'Alliberament Nacional de Catalunya, editant diversos opuscles de propaganda, $i$, en un aspecte poc conegut fins ara, havien passat a formar part durant uns

I2 Antoni Cardona i Roca, La tasca nacional del moment (19 d'abril de 1958) i L'acció armada per l'alliberament nacional (I2 de juny de 1960), San Fernando (Argentina), dipositats al Centre d'Estudis Històrics Internacionals (Barcelona).

Cercles. Revista d'Història Cultural, 22 (2019), 193-220.

ISSN: 1139-0158. ISSN-e: 1699-7468. DOI: 10.1344/cercles2019.22.1007. 
quants mesos del Directorio Revolucionario Ibérico de Liberación (DRIL). ${ }^{13}$

L'etnisme — assumit a l'origen, com veurem, per alguns nuclis que volien combatre situacions «d'alienació nacional»— feia referència a actituds individuals i moviments collectius vinculats a la dignificació de cultures minoritzades enfront de l'acció d'un «colonialisme interior» estatal. Segons l'obra de l'antropòleg Fredrik Barth - en destacar els signes que semblen constituir el nucli diferencia-

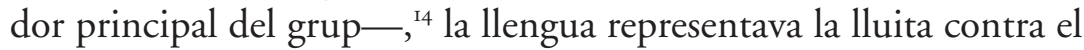
colonialisme lingüístic i, per extensió, la resposta a la residualització folklòrica d'una identitat cultural percebuda com a identitat nacional. Així, a partir dels anys seixanta, en el cas gallec s'aprofundí en el fenomen «lusista», és a dir, la proposta d'incloure dins els rengles nacionals la realitat portuguesa. També cal destacar, malgrat l'escàs ressò, la posició de Federico Krutwig — segons la zona de màxima expansió històrica de l'eusquera- a l'hora d'integrar dins l'àrea nacionalitària basca el Bearn, la Rioja o part de Cantàbria.

Cal remarcar, en definitiva, la socialització dels Països Catalans, territori nacional complet d'acció cultural i política. Esdevingué un referent fonamental per fer de la lluita independentista una empresa global. D'altra banda, la cartografia del topònim operà com a capital simbolicopolític amb l'objectiu de bastir un imaginari alternatiu — nou marc mental de representació, doncs — al simbolisme

I3 El DRIL fou una organització composta fonamentalment per militants portuguesos, com el capità Henrique Galvão, i gallecs, com Xosé Velo Mosquera. Es feu famosa, a banda d'alguns atemptats a Madrid, Barcelona i el País Basc el 1960, per haver portat a terme a començaments de 196I el primer segrest polític d'un transatlàntic en alta mar, el Santa Maria, amb 650 passatgers a bord, amb l'objectiu de denunciar les dictadures peninsulars de Salazar i Franco. Fermí Rubiralta i Casas, Un conspirador independentista. Joaquim Juanola i Massó (I89I-I967), Barcelona, Llibres de l'Índex, 2019.

I4 Fredrik Barth (comp.), Los grupos étnicos y sus fronteres, Ciutat de Mèxic, Fondo de Cultura Económica, 1976. 
polític contingut en la cartografia oficialista estatal. La politització de la identitat cultural esdevingué una fita en el que significava la lluita d'alliberament nacional.

\section{Referents ideològics fundacionals del PSAN}

L'FNC, l'organització política que des de la immediata postguerra hegemonitzà l'espai independentista, sortí beneficiat de l'embranzida al si de les bases catalanistes arran de la campanya contra el director de La Vanguardia Española Luis Martínez de Galinsoga entre juny de I959 i febrer de 1960. Aquest context de mobilització explicava que el partit es trobés en condicions de convocar un estratègic Consell Nacional. Donant per completada la seva reorganització després de la «hibernació» dels anys cinquanta, s'aprovaren una sèrie de nous plantejaments dins aquest espai polític, entre els quals cal destacar, sens dubte, la clara i oberta reivindicació de la independència de Catalunya, arraconant definitivament l'ús del terme "separatista», i l'assumpció dels Països Catalans com a àmbit unificat d'acció. ${ }^{\text {Is }}$

Aquest marc també explica, però, que, d'ençà del segon terç dels anys cinquanta i el primer terç dels anys seixanta, es produís l'entrada a l'FNC d'una generació de joves militants, estructurats, com hem assenyalat, en una secció universitària pròpia: el BEN. Fou una fornada de nous militants la que efectuà una «revolució teòrica» dins

I5 Fermí Rubiralta i Casas, Joan Cornudella i Barberà (I904-I985). Biografia política. 50 anys d'independentisme català, Barcelona, Publicacions de l'Abadia de Montserrat, 2003; Fermí Rubiralta I Casas, «De la hibernació a la normalització política (I948-I978)», dins Daniel Díaz i Esculies, Fermí Rubiralta i Casas, Jaume Renyer Alimbau (2006), Una història del FNC. 1940-I99o, Lleida, Pagès, 2006; Robert Surroca I Tallaferro (coord.), Memòries del Front Nacional de Catalunya. Cavalcant damunt l'estel, Barcelona, Arrel, 2006, i Roger Prims i Vila, De la fosca al desvetllament. El Front Nacional de Catalunya a la dècada dels cinquanta, Barcelona, Publicacions de l'Abadia de Montserrat, 2008. 
l'antiga organització, la qual cosa comportà, al capdavall, la constitució d'un nou partit. La nova situació interna s'explicava sobretot per una conjuntura definida per l'assumpció del materialisme històric, per la perspectiva d'anàlisi que aportaven els moviments d'alliberament nacional $i$, en conseqüència, per les diferències ideològiques i estratègiques existents entre sectors de joves militants i l'àmbit de direcció, compost majoritàriament pels quadres que havien creat l'organització als anys quaranta.

Cal observar, però, com s'anà gestant el nou partit, a fi de comprendre com s'hi anà forjant una línia teòrica de treball. Sembla ser, doncs, que el sexenni anterior al finalment no celebrat I Congrés Nacional de l'FNC (1967) és prou explicatiu per anar enllaçant el relleu generacional, i d'estratègia política, que, a la fi, abocà a la formació d'un partit nou, cosa que, en principi, no era prevista. Segons un dels fundadors del PSAN, Josep Ferrer, el qual s'incorporà a l'FNC el 1958, la gestació de la nova formació no fou immediata:

La proposta del PSAN sobre l'alliberament nacional i de classe, és a dir, la diguem-ne «teoria» que va elaborar i va difondre, és molt anterior a la constitució formal del PSAN mateix. Es va anar pastant sobre la marxa, del 1960 al 1967 , dins l'FNC, no pas amb la idea de fundar un partit nou, sinó de «reconvertir» un partit de patriotes, de caire més aviat liberal, en un partit revolucionari de masses.

Aquesta proposta teòrica es va anar pastant amb elements molt heterogenis sobre la base de la teoria marxista de la societat i de la història, sobre la base de la substantivitat històrica i social del fet nacional i sobre la base de la concepció dels Països Catalans com una societat nacional (és a dir, formada històricament, etc., etc.). Naturalment, vam anar cercant aquells elements que responien més a les nostres necessitats: el marxisme dels països sota dominació dels imperis austríac o rus, o bé sota els grans imperis colonials aleshores contemporanis. I vam rebutjar les concepcions essencialistes de nació, que obviaven la 
lluita de classes dins aquesta, i igualment la concepció leninista i afins, que valoraven les lluites nacionals merament en funció de l'interès d'una revolució social. La mica d'originalitat que pogués tenir la nostra amalgama d'elements, certament molt heterogenis, era en la dosificació que en vam fer per a adequar-los, suposadament, a la realitat del país sobre el qual volíem incidir. ${ }^{16}$

Hom pot constatar com s'anà construint un espai ideològic de debat que fou bastit, és clar, segons les característiques nacionals. Cal destacar, segons Ferrer, la influència dels casos d'opressió nacional, sota imperis, a l'est d'Europa, i de l'emergència dels alliberaments anticolonials. Aquests referents es difongueren - aprofitant infraestructures indirectes proclius a la consciència cultural i política- a través de bases militants, encara sota l'àmbit de l'FNC:

La dita elaboració [teòrica] es va fer molt improvisadament, sobre la marxa, és a dir, a mesura que «descobríem» els elements que consideràvem d'interès per a subvenir a l'argumentació que feiem servir en la tasca de proselitisme. I la vam fer unes quantes persones molt concretes. Bàsicament, va començar amb un petit nucli format per gent universitària, de les facultats de Dret, Lletres i Ciències (públicament agrupats com a Bloc d'Estudiants Nacionalistes, BEN) i un nucli de gent de l'Escola Massana que es lligà amb els universitaris; el primer mitjà d'expansió va ser la promoció de classes de català, tant dins la universitat (sota l'empara del SEU a Dret i sota l'empara de la càtedra del [professor] Antoni Comas, a Lletres i Ciències), com fora de la universitat, en aquest cas, semiclandestinament. Aquest primer nucli s'expandí cap al Vallès Occidental i cap al Maresme, i originà un segon nucli, constituït per gent de Sant Andreu i encontorns, que s'expandí cap al Vallès Oriental i que, sobre la base de les primeres elaboracions

I6 Contestació per correu electrònic de Josep Ferrer al qüestionari sobre els referents ideològics fundacionals del PSAN, I de maig de 20I9. La cursiva és nostra. 
del nucli originari, dugué una línia d'elaboració força autònoma, sobretot en el que en podríem dir "teoria estratègica». ${ }^{17}$

La fixació d'uns nuclis de militància territorial culminà amb el debat dels principis elaborats al si del no reeixit I Congrés Nacional de l'FNC, forçat per les bases que donarien lloc al nou partit, mentre que els quadres històrics del Front no hi eren reticents, "per evitar», segons Josep Ferrer, «un trencament que ja es veia venir». El nou document estratègic —esdevingut la Declaració política de principis_ posat a debat fou admès per un $80 \%$ dels militants de l'FNC. Aquest percentatge, doncs, constituí el PSAN. El document recollia la necessitat de bastir una "esquerra independentista» que anés des del trotskisme fins a la socialdemocràcia, per bé que una segona versió del text, la definitiva, faria al.lusió a l'assumpció del leninisme. «Aquesta pugna, latent ja dins l'FNC, tancà aquelles perspectives més àmplies i permeté una concepció "hegemonista” del partit dins la societat». ${ }^{.8}$

Arran, doncs, del nou Consell Nacional del 2i de setembre de I968, es constatà el trencament definitiu a l'FNC. Com a conseqüència d'això, pocs mesos després, el març de 1969, en una reunió del sector dissident celebrada al domicili de Carles-Jordi Guardiola, sortia al carrer una nova formació política que prengué el nom de Partit Socialista d'Alliberament Nacional dels Països Catalans.

I7 Ibidem.

I8 Ibidem. 


\section{Referent determinant: moviments d'alliberament contracolonials}

[De l'FNC al PSAN] Els nostres temes d'interès feien referència a diferents moviments populars revolucionaris (entre d'altres, Malcolm $\mathrm{X})$. També llegíem amb interès Gramsci, Chomsky, Samir Amin, Sartre, a més dels clàssics del marxisme (Marx i Engels) i del comunisme (Lenin i Mao). Sobre el dret a l'autodeterminació, Lenin i Andreu Nin. Sobre moviments populars d'esquerra d'arreu del món, biografies d'«Edicions de Materials» i [assaigs] d'Edicions 62.

La recepció d'aquests moviments se situava en una concepció del desenvolupament desigual del capitalisme mundial, definit a partir d'un «centre», organitzador de l'espoliació de recursos i d'un nou esclavatge, i d'una "periferia», identificada en formacions socials receptores de l'explotació i ocupació metropolitanes - turisme especulatiu, concebut també com a colonitzador cultural; funcionariat estatal, i ocupació militar. Fou, sens dubte, el referent-crida dels moviments d'alliberament anticolonials (Cuba, Algèria, Vietnam) el que va exercir una influència més profunda sobre el conjunt dels nacionalismes alliberadors a l'Europa Occidental (Catalunya-Nord i Còrsega contra l'Illa de França; Catalunya-Principat, Galícia i el País Basc del Sud contra l'Estat espanyol). Es produiia el que alguns autors definien com «una inversió de la tendència difusionista, mitjançant la qual la influència ideològica i el transvasament d'instrumental conceptual no es feu d'Europa cap a la periferia, sinó dels països de la periferia vers els estats del centre de l'hemisferi nord». ${ }^{19}$

i9 J.F. Marsal, F. Mercadé, F. Hernández i B. Oltra, La nació com a problema. Tesis sobre el cas català, Barcelona, Edicions 62, 1979, p. 37.

Cercles. Revista d'Història Cultural, 22 (2019), 193-220. ISSN: 1139-0158. ISSN-e: 1699-7468. DOI: 10.1344/cercles2019.22.1007. 
Aquest espill contracolonial adquirí rellevància a l'Estat francès, on, segons testimonis directes,$^{20}$ alguns excombatents de la guerra d'Algèria començaren a establir parallelismes entre el procés d'explotació colonial i la situació de les aleshores definides com a «ètnies» minoritzades, fins a començar a qüestionar-se la pertinença a aquell Estat.

A partir d'aquest moment, moviments nacionals de tipus nou conclogueren de les lluites anticolonials una estratègia comuna i elements conceptuals a partir dels quals podien analitzar la pròpia realitat nacional minoritzada. De fet, el PSAN recollia la influència del doble alliberament derivada de la praxi política contra la metròpoli: nacional i de classe. ${ }^{21}$

En el sentit de formació teoricopolítica, el text clandestí Justificació de Catalunya (1958), de Josep Armengou, va exercir una indubtable influència en la trajectòria independentista de l'FNC, atès que assumia conceptes de moviments nacionals de la "periferia» del sistema mundial quan parlava de «la doble alienació, nacional i de classe» o, més directament encara, quan apellava a la lluita armada d'alliberament nacional, "tot i que com a últim recurs». ${ }^{22}$

Un element d'anàlisi per descriure la situació que patien les minories minoritzades a l'Europa Occidental fou el concepte de colò-

20 Jean-L. Davant, Askapen mugimendu baten inguruan izandako esperientzia. Algeriako gerla, Bilbao, IPES, 1985 .

2I Josep Ferrer aporta els següents autors llegits: Karl Marx, Manifeste du Parti Communiste, suivi de "Les luttes de classe» (1962); Isaiah Berlin, Karl Marx. Sa vie, son oeuvre (1962); Henri Lefebvre, Le marxisme (1960); André Gorz, La morale de l'histoire (1959); Mikhail Bakunin, La liberté. Choix de textes (1965); Georges Bourgin i Pierre Rimbert, Le socialisme (1962), i Raymond Aron, Dimensions de la conscience historique (1965) (correu electrònic, I de maig de 2019).

22 Josep Armengou i Feliu, Justificació de Catalunya, Barcelona, La Magrana, I979, p. 245. També, Josep Nogueras I Canal, «Mn. Josep Armengou (Berga: 19io-1976). Un pensament al servei de l'Església i del nacionalisme català", Afers. Fulls de Recerca i Pensament, vol. 7, núm. I3, 1992, pp. I77-190. 
nia. Cal, en aquest sentit, remarcar l'estudi de Federico Krutwig, Vasconia (1963), on l'autor getxotarra d'origen alemany establia la situació colonial d'Euskadi. ${ }^{23}$

Una translació semblant, referida a una situació minoritzada en què el mirall colonialista semblava prou més adient —Galícia-, constava a l'assaig $O$ atraso económico de Galicia, de Xosé Manuel Beiras. Partia de la denúncia de la dependència colonial gallega exercida en un marc sense fronteres polítiques com a colonialisme «interior, doméstico, metropolitano». L'anàlisi fou assumida durant el tardofranquisme per organitzacions com la Unión do Povo Galego (UPG) i el Partido Socialista Galego (PSG). La influència de la posició de l'occità Robert Lafont, coneguda per Beiras a partir de 1966 arran dels seus estudis d'Economia a l'Estat francès, hi resultava prou patent, tot i que el líder galleguista la matisaria anys més tard, tot reconeixent que $" O$ atraso e un livro mais marxista que lafontiano, ainda que, evidentemente, a linguaxe utilizada non podia por de manifiesto por razons de censura certas claves lexicas ou conceptuais de corte puramente marxista». ${ }^{24}$

Amb tot, el concepte de colonialisme interior - havia fet fortuna a partir d'una vaga a les mines de Decazeville l'any 1962 - esdevenia un element central de tot un quadre analític de la situació de les nacions minoritzades a l'Europa Occidental, especialment Occitània, analitzada sociològicament i política per Robert Lafont i Alain Touraine. ${ }^{25}$

23 Fernando Sarrailh de Ihartza (pseudònim de Federico Krutwig Sagredo), Vasconia. Estudio dialéctico de una nacionalidad. Buenos Aires, Norbait, I963.

24 Xosé Manuel Beiras Torrado, $O$ atraso económico de Galicia, Vigo, Galixia, 1972, i Miguel Anxo Fernán-Vello i Francisco Pillado Maior, A nación incesante. Conversas con Xosé Manuel Beiras. Barcelona, Sotelo Blanco, I990, p. 79-80.

25 Les obres més destacades de Robert Lafont foren, sens dubte, La Révolution régionaliste, París, Gallimard, 1967 (edició en català, amb pròleg de Manuel Cruells, Barcelona, Aportació Catalana, 1968), i Sur la France, de 1968, traduïda al català amb el títol Per una 
S'ha de dir, però, que, pel que fa al PSAN, fos per la seva més tardana aparició cronològica respecte de les homòlogues formacions basca i gallegues ETA, UPG i PSG, o per la dificultat d'aplicar mimèticament un quadre explicatiu de tipus colonial a una realitat econòmicament més desenvolupada, l'assumpció dels elements conceptuals d'anàlisi dels moviments d'alliberament nacional seria més matisada, i, en qualsevol cas, més influïda per un autor com Robert Lafont, que no pas directament pels teòrics més destacats, per bé que llegits, de les lluites anticolonials, com seria el cas de Mao Zedong i Ho Chi Minh. També foren analitzats referents relacionats amb el colonialisme francès a la Mediterrània, com Frantz Fanon (Les damnés de la Terre, esdevingut assaig de referència) i Albert Memmi (Portrait du colonisé, précédé de portrait du colonisateur). ${ }^{26}$

Un altre concepte provinent dels teòrics de les lluites d'alliberament nacional, que de manera nova empraren els membres fundadors del PSAN, fou "alienació nacional», definit com la situació nacional «hipotecada a una altra sobirania aliena que impedeix la seva pròpia expressivitat i l'exercici de la pròpia sobirania». ${ }^{27}$ Com destacava Josep Ferrer «es tracta paradoxalment d'un concepte ben europeu, d'origen hegelià i encuny marxià, després d'haver identificat classe oprimida amb nació oprimida, pas lògic de veure en la classe alienada de Marx una nació alienada». ${ }^{28}$

teoria de la nació. El cas de França, Barcelona, Edicions 62, 1969. D’Alain Touraine en destaquem El País contra el Estado. Las luchas occitanas, València, Institució Alfons el Magnànim, 1983 .

26 Fermí Rubiralta i Casas, «Miralls del catalanisme. El Tercer Món, un estímul del final dels seixanta», El País, 2 de maig de I99i, i Fermí Rubiralta i Casas, "Lindependentisme català portes enfora: referents europeus i perspectiva històrica internacional», Revista de Catalunya (Barcelona), núm. 217, 2006, p. 25-4I.

27 Imma Tubella i Eduard Vinyamata, Diccionari del nacionalisme, Barcelona, La Magrana, I978, p. 35.

28 Josep Ferrer, «Els Països Catalans, com a pròleg», dins Imma Tubella i Eduard Vinyamata, Les nacions de l'Europa capitalista, Barcelona, La Magrana, I977, p. I7. 
En aquest sentit, el document que els futurs dirigents del PSAN havien defensat davant la vella guàrdia del Front — que serví de base per a la redacció de la primera Declaració política de principis de la nova formació- recollia aqueix concepte en el primer apartat, titulat «Esbós per a un plantejament teòric». Hi situaven l'alienació en un doble nivell, de classe i nacional, per la qual cosa el combat de la nova formació independentista catalana «forçosament anirà a lligar ambdues formes d'alliberament, que inclou tant l'objectiu de la unitat dels Països Catalans com la independència i la construcció d'un estat socialista català». Era un plantejament que tenia punts en comú amb la teoria de les tres etapes del moviment nacionalista de Joaquim Maurín i d'Andreu Nin. Es tractava del desbordament del nacionalisme burgès, mentre que el proletariat català començava a «descobrir» la seva funció nacional. Pel que feia al socialisme -es rebutjava per reformista la socialdemocràcia—, s'apostava per una via revolucionària «que lluiti no als parlaments, sinó a les fâbriques, les empreses, el camp o la ciutat», ${ }^{29}$ a partir d'una hipòtesi de treball que pretenia arribar a organitzar un «bloc històric d'alliberament nacional», amb la classe treballadora —urbana i rural— com a hegemònica.

En definitiva, l'etapa 1960-1967/1968 fou definitòria per capir els referents teòrics que foren analitzats per la militància constituent del PSAN. Es tractava de lectures, de manera individual o collectiva, que permetien de conèixer situacions polítiques sobre les quals es volia incidir. ${ }^{30}$

29 Josep Ferrer, Per l'alliberament nacional i de classe, 1978, p. 65.

30 Alguns autors estudiats per Josep Ferrer pel que feia a la qüestió nacional foren Antoni Rovira i Virgili, Història dels moviments nacionalistes (1912-1914) i Resum d'història del catalanisme (1936); Hans Kohn, Historia del nacionalismo (1949) i The Age of Nationalism. The First Era of Global History (1962); Jorge E. Spilimbergo, La revolución nacional en Marx (196I); Andreu Nin, Els moviments d'emancipació nacional (1935); Enric Prat de la Riba (ed.), La nacionalitat catalana (1910); Maximiano García Venero, Historia del naciona- 
En una conjuntura d'autocrítica i de reorientació organitzativa de les tesis comunistes no estalinianes, la recepció de l'esquema d'anàlisi tercermundista facilità una concepció menys rígida del bloc revolucionari: proletariat, menestralia, estudiants, pagesos i segments de la petita burgesia. Aquest bloc policlassista definia el "poble treballador", concepte utilitzat en els esquemes d'anàlisi de l'esquerra abertzale a partir del segon terç dels anys seixanta.

L'aplicació de l'esquema maoista de les quatre classes, desenvolupat fonamentalment en el context de la lluita contra la invasió japonesa, i àmpliament recollit per ideòlegs d'arreu del Tercer Món —i present també en l'esmentada obra de Federico Krutwig pel que fa al procés d'alliberament basc_-, facilitava la formació de fronts nacionals d'alliberament a l'Europa Occidental.

Pel que fa al PSAN - manifestà, de bon començament, que volia estendre la seva lluita a la classe obrera i a d'altres classes po-

lismo catalán (I793-1936) (1944); Pierre Vilar, La Catalogne dans l'Espagne moderne. Recherches sur les fondements économiques des structures nationales (1962); [PSUC], El problema nacional català. Ia part: Antecedents històrics (196I); Valentí Almirall, Lo catalanisme. Motius que'l llegitiman, fonaments cientifichs y solucions practicas (1886); Joan Fuster, Nosaltres, els valencians (1962); Rudolf Rocker, Nacionalismo y cultura (1954); Robert Bosc, La sociedad internacional y la Iglesia. Sociología y moral de las relaciones internacionales (1962); Boyd C. Shafer, Le nationalisme. Mythe et réalité (1964); Vladímir Ilitx Lenin, Problemas de política nacional e internacionalismo proletario (1966); Ióssif Stalin, La questione nazionale (1949); Jacques Droz, Le Romantisme politique en Allemagne (1963); Raoul Girardet, Le nationalisme français. I87I-19I4 (1966); Ernest Renan, Discours et conférences (1887); Antonio Gramsci, Sul Risorgimento (1965); M. Droz, Les nationalismes en Europe centrale de I87I à I939 (1963); Pierre Renouvin, Le sentiment national et le nationalisme dans l'Europe occidentale (1963); Lisandro Rubio García, «Las realidades y los mitos de un mundo de nacionalismos», Universidad. Revista de Cultura y Vida Universitaria (juliol-desembre 1965), i "Nationalisme et nationalismes contemporains», dossier de la Revue Française de Science Politique (juny 1965); Mao Zedong, Textes chinois (traduïts i presentats per Stuart Schram) (1963); Jean-Marie Domenach, "Le Canada français. Controverse sur un nationalisme», Esprit (febrer 1965); Yann Poupinot, Les Bretons à l'heure de l'Europe (196I); Castelao, Sempre en Galiza (ed. 196I), i Frantz Fanon, Les damnés de la Terre (I96I) (correu electrònic, I de maig de 20I9). 
pulars, com «els assalariats del camp i d'altres sectors sotmesos igualment a l'explotació monopolista, susceptibles de confluir amb el moviment obrer». Com sintetitzava l'apartat inicial de la seva primera Declaració política de principis, la nova formació independentista es definia com «l'organització política que es proposa la formació del moviment general de les classes catalanes per a la lluita d'alliberament nacional per mitjà d'una progressiva presa de consciència revolucionària global de la seva doble opressió nacional i de classe». ${ }^{3 \mathrm{I}}$

El darrer element característic de l'estratègia dels moviments d'alliberament nacional empeltats a nacions sense estat de l'Europa Occidental era l'assumpció de la lluita — o defensa — armada. La derivació dels fonaments de la lluita revolucionària tercermundista fou entesa per autors com Frantz Fanon com una mena de catarsi per a la nova nació per construir. Aquesta opció, però, no fou concebuda com a immediata pel PSAN, més enllà d'un plantejament merament teòric «reservat per a una etapa superior del procés de conscienciació de les masses». ${ }^{32}$

\section{Referent condicionant (I): moviment federalista europeu}

De manera paral.lela a l'influx de les lluites d'alliberament nacional del Tercer Món, sorgiren interpretacions lligades al moviment federalista europeu definides com a «etnisme», en adoptar el concepte «ètnia» com a base interpretativa de la qüestió nacional. Entre els «composantes objectives de l'ethnie», la llengua esdevenia per als et-

3I Declaració política de principis del PSAN dels Països Catalans, març de 1969, p. I.

32 Fermí Rubiralta i Casas, Orígens i desenvolupament del PSAN. 1969-I974, I988, p. 128 .

Cercles. Revista d'Història Cultural, 22 (2019), 193-220.

ISSN: 1139-0158. ISSN-e: 1699-7468. DOI: 10.1344/cercles2019.22.1007. 
nistes «la plus importante», desplaçant, doncs, la raça i altres factors biològics definidors. ${ }^{33}$

Aquest moviment agruparia autors com Alexandre Marc, François Fontan o Yann Fouéré, i, sobretot, l'obra de l'occità Guy Héraud L'Europe des ethnies, considerada com «la bíblia de l'etnisme», i que, dins les obligadament limitades coordenades de l'època a l'Estat espanyol, tingué una rèplica a casa nostra en diversos treballs de qui fou membre de l'Institut d'Estudis Occitans, Jordi Ventura. ${ }^{34}$ De fet, el moviment nacional català havia començat a entrar en contacte amb aquest corrent a partir de la formació del Consell Nacional Català a Mèxic l'any 1953, ben aviat liderat per Josep M. Batista i Roca. ${ }^{35}$

Durant la primera meitat dels anys seixanta hom assistí a una vindicació de les llengües minoritzades $\mathrm{i}$, en general, a una desclosa d'iniciatives culturals, que tenien la llengua com a fonament del treball cultural: la Nova Cançó, creació d'Òmnium Cultural, constitució de noves editorials, publicacions impreses en català o campanyes d'impuls del català a l'escola. ${ }^{36}$ Aquesta infraestructura, o bloc d'acció cultural, era un suport, si es vol indirecte, a la irradiació del treball polític del PSAN.

Associat normalment a aquests plantejaments de tipus etnista, es desenvolupà un corrent de defensa de l'europeisme -entès com a referent de l'Europa dels Pobles_-, fins a formar el que es conegué

33 Guy Héraud, L'Europe des ethnies. París, Presses d'Europe, I963, p. 39.

34 Ibidem; Jordi Ventura i Subirats, Les cultures minoritàries europees, Barcelona, Selecta, 1963; Jordi Ventura i Subirats, Les llengües europees, Barcelona, Aportació Catalana, 1963, i Jordi Ventura i Subirats, Els catalans i l'occitanisme, Barcelona, Aportació Catalana, 1964.

35 Víctor Castells i Benosa, El Consell Nacional Català. 1953-1975, Barcelona, Consell Nacional Català, 2005 .

36 Joan Crexell i Playà, Català a l'escola. Les campanyes populars sota el franquisme, Barcelona, La Magrana, I998, i Carles-Jordi Guardiola i Noguera, Per la llengua. Llengua i cultura als Països Catalans, 1939-1977, Barcelona, La Magrana, I980. 
com a moviment federalista europeu. No per casualitat Edicions d'Aportació Catalana —impulsada per l'activista independentista Joan Ballester i Canals, qui esdevenia punt de relació i plataforma entre sectors intel.lectuals i polítics dels Països Catalans- publicà L'Europa en formació, a càrrec de tres dels teòrics més destacats d'aquest moviment. ${ }^{37}$

El model federatiu europeu — com a àmbit procliu a la recepció de les posicions dels moviments d'alliberament nacional— socialitzà el reconeixement de realitats etniconacionals pel que feia a la construcció d'un nou projecte europeu. En aquest sentit, començaren a sorgir una sèrie de plantejaments — desenvolupats al llarg de la dècada dels anys seixanta i començaments dels setanta-, com les euroregions. ${ }^{38}$

Aquest marc de treball cultural explicava, en part, que un bon coneixedor de la realitat catalana, Sergio Salvi, publiqués a Itàlia el seu transcendental llibre Le nazione proibite — referent en la formació de militants del PSAN_- en què posava de manifest la realitat de deu nacions minoritzades de l'Europa Occidental. ${ }^{39}$

Pel que feia a la internacionalització de les causes nacionals irredemptes, el PSAN-Provisional (1974) — primera escissió del PSAN_es vinculà a la tasca de coordinació amb moviments d'alliberament d'altres nacions. El primer de maig de 1975 signà un comunicat con-

37 Guy Héraud, Alexandre Marc i Yann Fouère, L'Europa en formació, Barcelona, Aportació Catalana, 1969, i Robert Surroca i Tallaferro, Joan Ballester i Canals (19131980). Al servei dels Països Catalans, Barcelona, Òmnium Cultural, 2007.

38 Ricard Pérez Casado, «Les euroregions, una opció», Serra d’Or, núm. 156, is de setembre de I972, p. 2I-23.

39 Sergio SAlvi, Le nazione proibite. Guida a dieci colonie "interne» dell'Europe Occidentale, Florència, Vallechi, I973, i del mateix autor, Le lingue tagliate, Milà, Rizzoli, 1975. Aquesta obra tindria un paral.lelisme en el llibre d'Imma Tubella i Eduard Vinyamata, Les nacions de l'Europa capitalista, 1977. Carles Castellanos i Josep Guia, cofundador del PSAN valencià, han confirmat (correus electrònics de l'ı d'abril de 2019 i del 24 de març de 20I9, respectivament) la influència de Sergio Salvi.

Cercles. Revista d'Història Cultural, 22 (2019), 193-220.

ISSN: 1139-0158. ISSN-e: 1699-7468. DOI: 10.1344/cercles2019.22.1007. 
junt amb la UPG gallega i amb el sector politicomilitar d'ETA. Amb aquesta acció, el PSAN-Provisional s'adherí a la Carta de Brest, generada el 3 de febrer de 1974 per la Unió Democràtica Bretona (UDB), la UPG i el moviment republicà irlandès (Sinn Féin).

\section{Referent condicionant (II): entre maig del 68 i els «fronts de lluita»}

El desenvolupament dels nacionalismes subestatals europeus conegué un cert punt d'inflexió a l'entorn de la revolta urbana manifestada el maig del 68, que incidí en posicions del PSAN. ${ }^{40}$ Maig del 68 que - no per casualitat tingué com a escenari principal l'Estat francès, ètnicament el més diversificat de l'Europa Occidental— suposà una mena d'esclat de tota una sèrie de fenòmens acumulats de temps enrere. $^{4 \mathrm{I}}$

En un ambient de defensa dels valors antiautoritaris i d'oposició oberta al model d'estat burgès $i$, doncs, al control social, s'activaren conceptes — autogestió i drets polítics - aplicables a les principals reivindicacions del que es concebia com a nacions oprimides. En aquest ambient cultural-polític, la presa de consciència nacional adquirí transcendència i evidencià capacitat transformadora i potencial revolucionari. ${ }^{42}$

40 Fermí Rubiralta i Casas, «L’independentisme català durant la dècada de 1960. Alliberament nacional i socialisme», dins Primer Congrés d'Història de l'Independentisme Català, Reus, Centre de Lectura, 2007.

4I Jean-Paul Sartre, qui havia protagonitzat el desembre de I970 un primer acostament al fet nacional arran del Procés de Burgos, amb un pròleg al llibre de Gisèle Halimi, dedicà un número extraordinari a les nacions minoritzades de «'hexàgon»: «Minorités nationales en France», Les Temps Modernes, núm. 324-325-326, agost i setembre de i973, i JeanPaul Sartre, "Preface», dins Gisèle Halimi, Le procès de Burgos, París, Gallimard, I97I.

42 Fermí Rubiralta i Casas, «La repercusión de Mayo-68 en el movimiento nacionalista", Punto y Hora de Euskal Herria, núm. 516, 1988. 
La revolució cultural xinesa esdevenia un important referent, dins una segona etapa maoista posterior a la de la guerra d'alliberament contra l'ocupació japonesa. I, tal com succeí amb d'altres moviments polítics, en els grups i formacions polítics sorgits al començament dels anys setanta arreu de l'Europa Occidental, al PSAN seria patent la influència leninista, resposta paradoxal al buit creat pel desenvolupament de formes i continguts de tipus autònom amb posterioritat al maig del 68.

En conseqüència, la progressiva radicalització del discurs i la pràctica política esdevingué un fenomen visible al si del PSAN. A partir de 1972 s'inicià dins d'aquesta organització un intens debat entorn del feble creixement i l'escassa penetració aconseguits en els seus tres anys de vida, $\mathrm{i}$, dos anys després, s'hi originaria la primera escissió a la irlandesa entre l'oficial i els provisionals.

Els interrogants provocats per la constatació d'aquesta escassa penetració crearen dins el partit un corrent d'opinió favorable a una revisió de molts aspectes de la línia política i un canvi radical en les formes d'actuació del partit. S’impulsà, com a resultat, la dinamització de seccions —o fronts de lluita sectorials — i la publicació de butlletins específics: el maig de 1972, la secció de barris de Barcelona tragué a la llum Barris en Lluita, per primera vegada en edició bilingüe catalana i castellana, amb voluntat d'incidir en àmbits metropolitans amb influx de nova migració; el setembre de 1972, Vallès en Lluita, òrgan d'expressió de les Comissions d'Activitats Cíviques del PSAN; al Prat de Llobregat, des de febrer de 1973, s'edità El Pla en Lluita; i, pel que respecta als estudiants, aquell mateix mes i any, la secció corresponent publicava Estudiants en Lluita, i a partir del maig sortiren al carrer El Camp en Lluita i Obrers en Lluita, mentre que de manera prèvia s'articulà la secció juvenil sota el nom de Joventuts Revolucionàries Catalanes, que editaren el butlletí Joves en Lluita. Aquesta pràctica, que havia d'incrementar la presència del PSAN, es reflectí en les posicions del portaveu oficial Lluita, en la radicalitat 
de les accions públiques, una necessitat d'intensificació de la militància i obligats canvis de residència com a mesura de previsió i seguretat per les previsibles accions repressives policials.

La necessitat de visibilitat del partit en espais de lluita comportà un debat al voltant de concebre el tipus d'organització que s'havia de desenvolupar. Les divergències, ara, a diferència de l'escissió provocada dins el Front, no responien a qüestions de tipus teòric, sinó a diferents criteris estratègics, tàctics i orgànics, i per aquesta mateixa raó, en contraposició a la «tranquil.litat» que acompanyà el naixement del PSAN, sovintejarien les contradiccions internes, per bé que no n'hi hagué únicament, atès que existí la tesi, al si del sector que se n'escindí, perquè la fi de la dictadura no comportà la ruptura democràtica: calia explicitar l'oposició al continuisme del franquisme, aleshores sota la forma monàrquica, $i$, en conseqüència, manifestar l'oposició al seguidisme que hi efectuà el que es concebia com a bloc reformista, encapçalat al Principat pel PCE-PSUC i el PSOE-PSC.

L'escissió al si del PSAN seria un fet, concretat a la reunió de l'Assemblea de Representants del I4 de març de 1974. Davant el sector que a partir d'aquest moment seria conegut com a oficial, els militants dissidents, a la manera irlandesa, passarien a denominar el nou partit PSAN-Provisional (1974-1979). ${ }^{43}$ Però aquesta conjuntura la resta fora dels objectius d'aquest article.

43 Carles Castellanos i Llorenç, Reviure els dies. Records d'un temps silenciat, 2003. Fou precisament entorn d'aquesta conjuntura que Carles Castellanos, un dels principals impulsors del PSAN-Provisional, redactà l'opuscle — amb quatre edicions entre desembre de 1974 i setembre de 1976-El fenomen nacional, reflexió al voltant de les característiques i els efectes de l'opressió nacional en les nacions sense estat, reelaborada anys després sota la forma de llibre a Carles Castellanos i Roger Castellanos, El fenomen nacional. Fonaments teòrics i pràctics del moviment nacional-popular als Països Catalans, Barcelona, Edicions del 1979, 20I5. 


\section{Conclusions}

En l'àmbit metodològic, l'anàlisi de les matrius ideològiques del PSAN evidencia que cal establir, de forma substantiva, la «reconstrucció d'elements teòrics referencials» des de la mateixa assumpció dels postulats segons la pràctica militant. És, doncs, la praxi la que condiciona la teoria. I no a l'inrevés. Especifiquem aquest aspecte perquè les síntesis teòriques al voltant dels moviments d'alliberament nacional acostumen a establir conclusions a posteriori, que poden induir a obviar el context coetani en què foren assumides determinades posicions. Com afirma un cofundador del PSAN, «el pensament sobre la qüestió nacional l'extrèiem de les lluites d'alliberament que anàvem coneixent i analitzant». ${ }^{44}$ Aquesta és la base de la qual es parteix de manera fefaent, si hom vol concretar un marc teoricopolític que superi el formalisme (teorètic). En aquest marc, considerem que l'etapa final dels anys cinquanta, fins al frustrat I Congrés Nacional de l'FNC (1967) i les conseqüències polítiques immediates, és del tot central per comprendre el perquè de la formació d'un partit nou. En part, doncs, el PSAN fou el resultat de les contradiccions internes no superades al si de la formació independentista matriu fundada el 1940. La constitució del PSAN, amb el lema «Independència, Socialisme, Països Catalans», suposà, per primera vegada després de l'ensulsiada de 1939 — i sota el tardofranquisme—, la definició de l'independentisme des del marxisme. El partit plantejava així un doble alliberament: nacional i de classe. D'aquesta manera, situà l'anàlisi d'una societat nacional com a concreció de les lluites de classe. No existia, doncs, «separació» analítica ni estrategicoorgànica entre «fet nacional» i «fet social». Aquesta concepció fou deutora dels nous corrents culturals i ideològics sorgits arran de la lluita dels moviments anticolonials, com també de l'anàlisi de les contradiccions i

44 Carles Castellanos i Llorenç (correu electrònic, II d'abril de 20I9).

Cercles. Revista d'Història Cultural, 22 (2019), 193-220.

ISSN: 1139-0158. ISSN-e: 1699-7468. DOI: 10.1344/cercles2019.22.1007. 
respostes de lluita enfront dels estats espanyol i francès. El marxisme adoptat fou de doble matriu: una d'abast internacional, forjada al si de les lluites emancipadores a la "periferia» del sistema econòmic capitalista mundial, i una altra d'endògena, conseqüència de l'aplicació del materialisme històric al si de les lluites — i formes d'organització i de resposta - concretades en la societat nacional (catalana). Aquesta lectura interna comportà la recuperació de referents independentistes dels anys trenta, com fou el cas de les propostes obreristes de l'Estat Català Partit Català Proletari de Jaume Compte. Amb la formació del PSAN s'obria un horitzó estratègic de superació del catalanisme polític, atès que era concebut com a estratègia reformista i modernitzadora de l'Estat espanyol. ${ }^{45}$

Cal valorar, en conseqüència, la socialització de nova simbologia que arriba fins als nostres dies. Simbòlicament, la matriu comunista del PSAN prengué com a forma política d'identificació la senyera amb l'estel roig.

Per altra banda, cal remarcar que la constitució del PSAN comportà — per primera vegada i com a única organització- la implantació de la lluita d'alliberament al conjunt dels Països Catalans del Sud. Posteriorment, la constitució, el I979, d'Independentistes dels Països Catalans (IPC) a Rià del Conflent complementà l'àmbit de lluita a la Catalunya Nord. Simbòlicament, aquesta praxi territorial comportà l'assumpció del mapa dels Països Catalans, difós a començaments dels anys seixanta, fet previ a la constitució del PSAN. El símbol, doncs, es materialitzà en forma militant organitzada. Foren el PSAN i el PSAN-Provisional, juntament amb d'altres petits grups de la recentment creada esquerra independentista, els que impulsaren, com a lloc de memòria combatiu, la commemoració de l'iı de Setembre (d'ençà de 1977) al Fossar de les Moreres. El fet represen-

45 Eva Serra, «La història amb vocació de país», dins Testimonis del segle Xx, Vilanova i la Geltrú, El Cep i La Nansa, 20I0, p. 59. 
tava la projecció política d'un episodi de resistència al que es concebia com a fase històrica d'ocupació espanyola. L'aportació fonamental del nou independentisme revolucionari, concretat en el període analitzat, palesà que la suposada «fi» de la lluita antifranquista no implicava la fi de l'opressió nacional. La contradicció primordial era combatre políticament l'opressió nacional. La democràcia formal burgesa espanyola constituiia una "presó de pobles», la qual cosa evidenciava la contribució de l'estratègia alliberadora a l'hora de fonamentar l'organització política des de la nació en lluita. Tot just un turning point de concepció — i mentalitat — orgànica, definida en totes les seves dimensions de mobilització. ${ }^{46}$

46 Vegeu, sobre aquest aspecte, el balanç de l'acció de l'independentisme i de l'esquerra nacional sota el tardofranquisme i la reforma política fins a les eleccions autonòmiques al Principat el març de 1980 a «L'esquerra nacionalista avui», Quaderns d'Alliberament (Barcelona, La Magrana), núm. 7, I982, pp. 158-253.

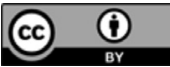

Copyright (C) 20I9. Aquesta obra està subjecta a una llicència de Creative Commons mitjançant la qual qualsevol explotació n'haurà de reconèixer els autors, citats a la referència que apareix a l'inici del document.

Cercles. Revista d'Història Cultural, 22 (2019), 193-220.

ISSN: 1139-0158. ISSN-e: 1699-7468. DOI: 10.1344/cercles2019.22.1007. 